\title{
THE NATURE OF WORK FOR EMPLOYEES IN A VIRTUAL ORGANISATION: THE VIRTUAL WORKER
}

\author{
VI-LAM TRUONG ${ }^{1}$ and BRIAN J. CORBITT ${ }^{2}$ \\ ${ }^{1}$ Price Waterhouse Coopers, Australia \\ ${ }^{2}$ School of Information Systems, Faculty of Business and Law, Deakin University, Australia
}

Abstract: This exploratory study aims to develop and offer some deeper understanding of the impact on work created by virtual organisations. This study seeks to understand: what are the advantages in the virtual arrangement that attracts the virtual workers? And what aspects of the virtual worker enable them to function in this working environment? Although the meanings of the virtual organization are varied, an adapted definition of the characteristics of the virtual organization is presented. The salient aspects of the virtual organization is the flexibility to meet the changing environment, its effectiveness in using electronic communication and the leveraging of strategic partnerships. Understanding virtual work is important as e-commerce and e-business strategies are adopted and implemented in organizations where flexible work practice is a key component of the business strategy.

\section{INTRODUCTION}

This study explores the nature of work for the virtual worker and offers some understanding of the impacts that working in the virtual environment can have on the virtual worker. This understanding may prove useful for researchers and practitioners. For practitioners, such knowledge and deep understanding will allow better consideration when developing virtual work arrangements, especially in e-commerce and e-business flexible working arrangements. Understanding the implications and nature of such work will allow academics to better cater for further research in this field. The aim of

The original version of this chapter was revised: The copyright line was incorrect. This has been corrected. The Erratum to this chapter is available at DOI: 10.1007/978-0-387-35692-1_36 
the study is to develop a deeper understanding of the impacts of virtual organisations on the virtual worker.

There is an increasing trend towards the adoption of the Internet and teamwork in modern organisations. New methods of conducting business have begun to revolutionalise work. VeriFone, a multinational organisation, operates with company management distributed globally (Stoddard \& Donnellon, 1997). Microsoft uses virtual teams to support global corporate customers with interdependent customer needs crossing country boundaries (Jarvenpaa, Ives, \& Pearlson, 1995). New organisational structures and working arrangements have increasingly been adopted. One of these new organisational structures is the Virtual Organisation. Castells (2001) argues that the new world of work is not only network but has encouraged the dissipation of work tasks.

\section{VIRTUAL ORGANISATIONS}

The meaning of what a 'virtual organisation' is varies. Definitions range from virtual communities that are free from geographical constraint (Van Alstyne \& Brynjolfsson, 1996), to an organisation in which there exists no boundaries, with teams formed at need and which often consists of members from different countries (Jarvenpaa, Knoll \& Leidner, 1998). Nohria \& Berkley (1994) define the virtual organisation as one without clear organisational boundaries, with electronically based communication and storage. Venkatraman \& Hendersen (1998) define virtualness as a strategic characteristic applicable to every organisation. Palmer \& Speier (1997) describe a stable virtual organisation where there is a permanent core, which lays down the rules for collaboration with partner organisations. Another description of virtual organisations involves organisations that come together when a customer approaches them with an order or problem. Temporary collaboration relationships and shared leadership are formed (Davidow \& Malone, 1992). Others define the virtual office to cover a variety of mobile and remote work environments (Davenport \& Pearlson, 1998). Christie \& Levary (1998) support that a virtual organisation involves continuously evolving networks of independent companies linked together to share skills, costs, and access to one another's markets and data.

These definitions provide an understanding into what virtual organisations' may be. For the purpose of this study, the researchers believe that certain characteristics are present in virtual organisations. Virtual organisations can exhibit certain attributes, which together make them more or less virtual. These attributes are represented in Table 1, adapted from Bultje \& van Wijk (1998) and Jansen, Steenbakkers \& Jagers (1999) and 
represent a workable definition of the virtual organisation for the purpose of this study.

Drawing on existing literature dealing with virtual teams and workers, it is evident that virtual workers share a common goal, without centralised buildings, physical plant, or other characteristics of a traditional organisation

\section{Characteristics of Virtual Organisations}

core competency based

network of independent organisations

boundary crossing

pooling of resources

sharing of knowledge

geographical dispersion

\author{
one identity \\ based on information \\ technology \\ no hierarchy \\ changing participants \\ participant equality \\ electronic communication
}

Table 1. Characteristics of the Virtual Organisation.

Adapted from Bultje \& van Wijk (1998) and Jansen, Steenbakkers \& Jagers (1999)

(Hartman \& Guss, 1996; Staples, Hulland \& Higgins, 1998); often operating across space, time and organisational boundary (Lipnacks \& Stamps, 1999; Christie \& Levary, 1998). The researchers propose then that the term Virtual Worker can be defined as: workers that perform their work at various locations, may be employed by a virtual organisation or work on assignments from various sources on a full-time basis.

\section{RESEARCH RATIONALE}

Virtual organisations have been made possible by the increasing sophistication of information and communications technology, providing new ways of conducting business (Dennis, Pootheri, \& Natarajan, 1998; Fritz, Narasimhan \& Rhee, 1998; Venkatraman \& Hendersen, 1998). Organisations once confined by geography and differing time zones are now able to enable tasks from remote locations and at anytime (Davenport \& Pearlson, 1998). New organisational structures and information technologies have impacted on the interactions of human and collaborative systems within and between organisations (DeSantis \& Monge, 1998; Grabowski \& Roberts, 1998). The Internet is the technology that has facilitated a solution where geographical distances and information exchange among people have 
been fundamentally altered (Van Alstyne \& Brynjolfsson, 1996; Castells, 2001).

Virtual organisations no longer conform to Weber's model of bureaucracy or Taylor's scientific management (Fritz, Narasimhan \& Rhee, 1998; Rittenbruch, Kahler \& Cremers, 1998). These new organisations require new sets of management techniques and acceptance of different issues including work. This exploratory study aims to develop a deeper understanding of the impact on work created by virtual organisations. Traditionally, research within the field of information systems that deal with virtual organisations has focused on virtual teams, groupware, and communication (Vandenbosch \& Ginzberg, 1997; Fritz, Narasimhan \& Rhee, 1998; Jarvenpaa, Knoll \& Leidner, 1998; Rittenbruch, Kahler \& Cremers, 1998). There is a need for further research about virtual workers in the virtual environment, which traditionally, has been neglected in the research community (Hill, Miller, Weiner \& Colihan, 1998). This study will enable a better understanding of the nature of work in order to aid further research in virtual organisations. In practice, human resource has long been regarded as a sustainable competitive advantage (Stroh \& Caligiuri, 1998). Issues are raised when a radical structures or work arrangements are implemented. These issues include renumeration, supervision, quality control, promotional opportunities, or choice in the matter. The aim of this study is to develop a deeper understanding of the effects of virtual work on the virtual worker.

This research uses techniques couched in an interpretivist epistemology. To develop a deeper understanding of virtual work, within a distributed work environment, it is clear that interpretivist view of research will allow the researcher to understand the phenomenon of virtual work and capture the richness of data needed to engage a deeper understanding. In selecting the research method to subscribe to for this study, the researchers paid particular attention to the aims of the study, to ensure that the method used was appropriate for the type of research and outcomes required (Hamilton \& Ives, 1982, Galliers, 1992; Shanks et al., 1993) to ensure rigor. As discussed above, the current research was based on the interpretivist tradition, although quantitative and qualitative methods contain many epistemological traditions (Yin, 1994; Lin 1998), qualitative methods were chosen for the current study. Quantitative research relies on the measurement of descriptive variables, to remove the effects of context, and to use inferential statistics in order to produce generalisable and reproducible results (Kaplan \& Duchon, 1988). In the current study, the aim is not to test theory or measure any descriptive variable from the data and thus quantitative methods were not adopted. Rather resultant data was analysed and assimilated in order to draw 
logical implications. Qualitative research methods were chosen instead, in order develop the implications and suggestion from the data.

Qualitative research focuses on the meaning in the context or natural setting of the study, and is oriented towards exploration and discovery where the researcher attempts to make sense of the situation (Patton, 1990; Myers, 1997). Categories and meanings emerge from the data collected as the researcher develops an understanding of the situation (Kaplan \& Duchon, 1988). The outcomes required by the researcher involve the discovery of important concepts, themes and implications, in the context of the virtual work environment. The study did not aim to, but did not consciously point the study away from, comparisons between virtual and conventional workplaces. The study aimed at developing a deeper understanding of the effects of virtual work in the context of virtual organisations.

Data collection was done through interviews using open-ended questions $\mathrm{s}^{25}$, which allowed the researcher to probe information and explanations from respondents to gain rich data. The researcher was able to stimulate the responses of the exemplars to be broader than that of a structured interview (Walsham, 1998), providing their view of the virtual environment. It also provides the ability to observe non-verbal cues and allows rapport and motivation for respondents to build (Williamson, 1999). Further, the researcher was able to control the focus of the interview and allowed the researcher the option to follow up on interesting leads in later interviews, perhaps in a further study to refine or test the findings of the current study. The interviews were held over a two-week period with the researcher meeting the participants for approximately 60 minutes. Other sources of information used by the researcher included press releases, the Internet, company documents and other sources of interest, regarding the virtual arrangement of the virtual worker.

There were three exemplars of virtual work drawn from a spectrum of distributed work arrangements. This concept is depicted in Figure 2. This forms a representative spread whereby themes and implications may emerge, despite the limited number of individual studies done.

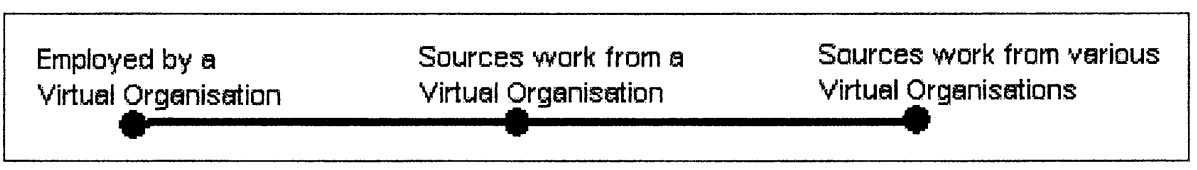

Figure 1. Spectrum of Virtual Arrangements 
Source: VL Truong (1999)

The use of three exemplars can be justified due to the rich data that was collected. In quantitative studies, the researcher knows beforehand the possible answers they would be able to receive, in qualitative research, the researcher cannot shield them from unknown information (Becker, 1996). The researcher of this study found that as the exemplars responded to the interview questions, more questions emerged which were probed and explored to extract further and richer information.

Although strictly speaking, there were only three case studies, after careful analysis of the data, the findings somewhat matched the findings in existing literature. According to Gummesson (1988), limited numbers of observations may not inhibit the findings to be generalisable, large amounts of generalisation may not lead to more meaningful generalisations. Generalisation from individual or many cases does not necessarily depend on statistical validity but the plausibility and cogency of logical reasoning used in describing and drawing conclusions from them (Walsham, 1993; McMaster \& Vidgen, 1995).

According to Walsham (1995), the aim of data analysis in the current study can be described as interpretive generalisation, whereby the researcher aims to develop concepts, theories and implications that are valuable in the context of virtual work other than the particular situations of the exemplars. The current study will mainly draw on the information elicited from the interviewees. After the interviews were conducted, the transcription to hardcopy was made and verified by the exemplars. Data analysis of the three case studies was a reiterative process of reading, re-reading, sifting, and discussion of the field data to identify themes and issues, similar to methods applied in Walsham (1998). The sifting and discussion of the data involved similar techniques used in case study analysis, which consist of single or multiple case studies with multiple levels of analysis (Yin, 1984), most notably within case and across case analysis.

Open coding of the interview transcriptions were performed first in order to break apart and fracture the data analytically, leading to grounded conceptualisation (Strauss, 1987). Essentially this involved a line by line breakdown of the text, whereby emergent themes and concepts emerged. The next step involved the "within case analysis" of creating stories ${ }^{26}$ from the data, or descriptions of the exemplar experience of virtual work; these stories are central to the generation of useful insight (Gersick, 1988; Pettigrew, 1988). The aim was to develop an intimate understanding of each exemplar experience in the process unique patterns emerge which allows generalisation across different exemplar experiences (Eisenhardt, 1989). 
The next phase involved the use of "cross case analysis" ${ }^{27}$ which further developed the generalisability of concepts emerged through analysis of common patterns across the exemplars (Eisenhardt, 1989). For example, a matrix including the exemplars and emergent concepts and implications was developed and analysed and was used to validate conclusions drawn. This analysis of the patterns emergent across cases forced the researcher to look beyond initial impressions evident in the data (Eisenhardt, 1989).

\section{DISCUSSION}

This study explores virtual work and its effects on the virtual worker. The literature on virtual organisations offers many insights to why organisations adopt virtual structures. However, little has been done in relation to what virtual organisations can offer the virtual worker. Two particular areas emerged from the analysis, the perceived benefits and problems that arise for the virtual worker, and the nature of the persona of the virtual worker.

\subsection{Benefits and disadvantages for the virtual worker}

This research would suggest the following about the benefits for the virtual worker.

\subsubsection{Flexibility and Autonomy}

Virtual organisations, due to its distributed nature can provide virtual workers with autonomy and flexibility (Davenport \& Pearlson, 1998; Hill et al., 1998). According to Davenport \& Pearlson (1998), mobile workers value flexibility and autonomy in virtual environments. Flexibility gives the virtual worker the ability to control when and how to work and autonomy provides the ability to control the output of work, providing virtual workers with a distinct advantage. Completing tasks independently without the assistance of others is extremely satisfying. One subject in Case Study 1 notes: "...ultimately a more satisfying way to work, because of the flexibility...the autonomy of work..."(Case Study 1 participant).

The data from this study suggests that flexibility and autonomy are important factors that attract workers to virtual situations. 


\subsubsection{Working Environment}

In virtual organisations, each member is skilled in a particular area, creating an enjoyable working environment. As the virtual organisation is non-hierarchical and decentralised (Ahuja \& Carley, 1998), each member is required to contribute significantly to each assignment (Christie \& Levary, 1998). Van Alstyne \& Brynjolfsson (1996) suggested that in the virtual community, all members are equal. This equality is also represented in some of the participants in that "...you don't get caught up in the politics and you have a specific time frame to finish off the work" (Case Study 2 participant). The subjects of the research suggest that, renumeration is performance based so non-productive, political games are useless in this environment. There will be limited politicking in the virtual organisation, as there are no benefits to the virtual worker who plays political games when performance is measured by productivity. This participants in this study suggests that in virtual organisations, due to its flat hierarchy and distributed structure, performance is more important than political manoeuvring. Each member is specialised in a particular area, they are respected in that area and this, according to the virtual workers studied, creates a good working environment.

\subsubsection{Career Objectives}

During the interviews, particular emphasis was given to the nature of assignments the virtual workers chose to conduct. All exemplars in the current study believe that the variety and scope afforded by virtual arrangements are advantageous for their career development. Their work and roles are not restricted as each assignment and assignment role is different, each has its own performance criteria and scope (Townsend et al., 1998). In one assignment they may be working for local government and in the next, providing their services to a major utilities company. One of the participants notes: "...if I were applying as a permanent position in to the utilities industry...I would not have gotten that...because I have different skill sets...in the interview I sold myself...now they offer me..." (Case Study 2 participant).

The virtual worker experiences a wide range of business environments and industries, giving the virtual worker the ability to build core skills and specialisations to improve their employability. Virtual workers are able to use these experiences to pursue particular interests or develop particular skills to market themselves in seeking further assignments. Career development opportunities in virtual environments are very attractive in allowing virtual workers to gain experience in a variety of industries. 
Virtual Worker

Interviews generated in this research not only identified positive outcomes from working virtually, they also highlighted some of the disadvantages.

\subsubsection{Getting Started and Keeping Afloat}

The stories in the data suggest that a disadvantage one for workers in many virtual organisations is that they do not strictly employ the virtual worker, rather they are contracted for a given period. Once this ends, the relationship between virtual worker and the virtual organisation also ends (Grabowski \& Roberts, 1998). One of the participants notes the nature of projects: "I work on multiple different tasks...multiple different projects. They tend to be short-term projects." (Case Study 1 participant). In these situations, management sees the virtual worker as third party employees (Dickerson, 1998), thus not many training or support facilities are offered. This may be because employee numbers are not fixed, increasing and decreasing when there are assignments. It is a personal issue for the virtual worker. In this situation, there may be a lack of organisational identity that binds the employee to an organisation (Wiesenfeld et al., 1998). One of the participants in Case Study 2 clarifies: "...one of the problems I face myself...if I don't work for two weeks...I don't get paid for two weeks...in (conventional) organisations...you still get paid for two weeks!" (Case Study 2 participant).

There are also costs associated with being a virtual worker, as one of the participants in Case Study 2 explains: "... you have to set up yourself to be in business for yourself like getting the work and buying the your own equipment to set up your SOHO... run your own business..." (Case Study 2 participant). Set-up costs to facilitate virtual work may be high. Marketing, training and accounting can be expensive. This discussion, albeit brief, supports Dickerson's (1997) findings that some disadvantages of virtual work involve the lack of training, support facilities and set-up costs, as virtual organisations need to be structured to achieve maximum flexibility for management (Dickerson, 1997).

\subsubsection{Career Management}

The flexibility afforded to the virtual worker may cause time management issues to arise. This research highlights the need for virtual workers to effectively manage their time, as often, they will not be able to walk away from the work. One of the participants clarifies: “...its difficult to set a particular time for your work...so work tends to impinge much more on your personal life...you can't really shut it away." (Case Study 1 
participant). This may be explained that the decision to put in time to complete assignments are the worker's. The interviews suggest they put in the maximum amount of time in order to complete the work, often neglecting other areas of their lives. Career wise, the flat or non-existent hierarchy (Ahuja \& Carley, 1998; Townsend et al., 1998), create difficulties in career advancement. One of the participants commented on the lack of career opportunities: "...less managerial career prospects...more team based...more responsibility..." (Case Study 3 participant).

New forms of organisations emerge as new technologies and methods of interactions are developed (Townsend et al., 1998), causing workers to alter their career advancement perspectives. This study suggests that disadvantages include the difficulty in career advancement as virtual organisations have flat hierarchies making upward movement difficult. It is suggested that the flexibility afforded by virtual organisations to the virtual worker dictates that they be adept at time management, lest they let work encroach on their personal lives.

\subsubsection{An Isolated Environment}

In virtual organisation literature, communication has been regarded as the medium that clarifies goals, relationships and responsibility between members (Grabowski \& Roberts, 1998). Communication creates organisational identity (Wiesenfeld et al., 1998). In the virtual environment, communication is conducted through electronic means, which hinders the development of trust (Jarvenpaa et al., 1998). Electronic communication, if not managed properly is a disadvantage of the virtual organisation (Davenport \& Pearlson, 1998; Fielding et al., 1998; Jarvenpaa \& Leidner, 1998). One of the participants notes: “...you interact...across the limited communication channels...much more restricted on the ability to communicate, particularly in non-verbal fashion". (Case Study 1 participant).

New members coming into the organisation are required to develop trust and relationships. If face-to-face interactions are not possible, the virtual worker must overcome these difficulties of electronic communications but the lack of physical cues makes this difficult (DeSantis \& Monge, 1998; Fielding et al., 1998). Reliance on electronic communications stems from the distributed nature of virtual work, as virtual workers work are isolated from each other. One of the participants explains:

"...because I'm here in Melbourne and it's difficult to interact with colleagues who basically are working out of Sydney." (Case Study 1 participant). 
The virtual worker must deal with this issue to work effectively. Often, this isolation is not between the virtual worker and colleagues, but also between the virtual worker and the client. This creates issues such as the building of trust, organisation identification and virtual team dynamics (Jarvenpaa et al, 1998; Wiesenfeld et al., 1998). The analysis of data from this study suggests that isolation and the reliance on electronic communications is disadvantageous to the virtual worker.

\subsubsection{Working Relationships}

Working virtually will involve isolated periods of work. Relationships developed between the virtual worker and the client are often limited, as there are usually neither time nor benefits for the virtual worker to build strong relationships. One of the participants explains: "I just get the job done according to my brief and try to do it well to move on to the next job!" (Case Study 2 participant). If he/she does a good job, the client may offer him/her additional work or a permanent position. Professional relationships are built between the virtual worker and the client through the interactions required in performing their tasks. This relationship is often adversarial. One of the participants explains: "you're always on an adversarial position with the clients because they're always trying to get the best deal and your always trying to sell them the biggest deal." (Case Study 3 participant).

The advantages of flexibility and autonomy are offset by the need to deliver an acceptable product in the end. Davenport \& Pearlson (1998) argue that a reason for organisations to adopt virtual structures is to increase productivity. The virtual workers of this study are often contracted for specific purposes within assignments. Being solely responsible, they are more accountable. New measures are needed for virtual arrangements (Ahuja \& Carley, 1998). One of the participants explains: "I will be paid for the work I produce, and if I were paid on an hourly rate, much more consideration would be given to my productivity." (Case Study 1 participant).

The analysis of the data suggests these disadvantages of virtual work, which includes the adversarial relationships with clients and the need to be more accountable. No comparison is made between virtual and conventional work, although this participant does speculate on the nature of conventional and virtual environment accountability. One participant noted that "...working in an office environment is that people are much more putting in time...being in the office is much more important...if you're a virtual worker, that's not work...you're not actually producing an output...as a 
virtual worker, you're much more measured by the output..." (Case Study 1 participant).

This section has highlighted, albeit briefly, the benefits and disadvantages experienced by the virtual workers studied. Disadvantages included the start up and ongoing costs of becoming a virtual worker, the limited support and the limited training opportunities. Career wise, the virtual workers studied felt the lack of organisational hierarchy limited their upward movement within the organisation. Working relationships were not easily built, either between members or clients, as limited benefits are provided to the virtual worker that develops these relationships. Often, client relationships developed are adversarial. The nature of virtual work requires the virtual worker to be better accounted in the work they perform. The distributed work environment relies on electronic means of communication as members of the virtual organisation are often geographically dispersed. The virtual worker must overcome the isolation of virtual work. Second, the disadvantage of electronic communication is that it requires the virtual worker to communicate and create meanings over limited communication channels that lack the physical cues of face-to-face interactions. The advantages and disadvantages identified in this study are summarised in Table 12. Overcoming these difficulties in the virtual environment requires that virtual worker to have certain attributes. The following section discusses what some of these attributes that create a persona of the virtual worker.

\begin{tabular}{|l|l|}
\hline Advantages: & Disadvantages: \\
\hline Flexibility of Work Arrangement & Lack of Support \\
Performance Based Renumeration & No Training \\
Autonomy of Work and Responsibility & Time Management \\
Career Development & Career Advancement \\
Interest and Skill Sets & Isolation \\
Not Paramatised & Adversarial Client Relationships \\
Respect vs Power & Electronic Communication \\
Working Environment & Accountability of Work \\
& Virtual Worker Set-up Costs \\
\hline
\end{tabular}

Table 2. Advantages and Disadvantages of Virtual Work.

\subsection{The persona of the virtual worker}

The discussion from here focuses on the other theme that emerged in the research, the persona of the virtual worker. The researcher proposes that the following aspects represent a cautious look into the persona of the virtual worker. It can generally be seen that there are several dimensions in the persona of a virtual worker. The dimensions depicted in Table 3 were found 
throughout the analysis of the data. Each of these is evaluated in detail in the following discussion.

\begin{tabular}{|c|c|}
\hline Working Methods & $\begin{array}{l}\text { Work Autonomously } \\
\text { Work Individually } \\
\text { Contribute to Teams } \\
\text { Self Directed } \\
\text { Self Reliant }\end{array}$ \\
\hline $\begin{array}{l}\text { Communication } \\
\text { Skills }\end{array}$ & $\begin{array}{l}\text { Communication Electronically } \\
\text { Communication Skills }\end{array}$ \\
\hline $\begin{array}{l}\text { Organisational } \\
\text { Experience }\end{array}$ & $\begin{array}{l}\text { Enjoy Being Part of Dynamic Organisations } \\
\text { Enjoy Challenge } \\
\text { Enjoy Change } \\
\text { Enjoy Work } \\
\text { Experienced in Change } \\
\end{array}$ \\
\hline Personal Traits & $\begin{array}{l}\text { Flexible } \\
\text { Good Manager of Self } \\
\text { Skilled } \\
\text { Task Oriented } \\
\text { Dedicated } \\
\text { Disciplined } \\
\text { Motivated } \\
\text { Work Ethic } \\
\text { Personality Match }\end{array}$ \\
\hline
\end{tabular}

Table 3: The Persona of the Virtual Worker.

\subsubsection{Working Methods}

This dimension focuses how virtual workers are required to work. Virtual workers work in isolation, apart from team members and alone. The attributes in this dimension enable the virtual worker to work effectively. Being able to work autonomously enables the virtual worker to plan and produce work according to their knowledge and skills. So one important attribute is to be able to work autonomously (Davenport \& Pearlson, 1998). One of the participants notes: “....autonomy. My style of work works best if I am left to get on with it." (Case Study 3 participant).

According to Christie and Levary (1998), the virtual worker must be selfdirected and self-reliant, as there is a need for them to resolve any complications by themselves. As the virtual worker often works in isolation from others, there is a need for them to work individually. This does not mean that the virtual worker cannot work in a team environment. On the contrary, they must be able to contribute to teams when it is required 
(Plishkin \& Romm, 1997; Hill et al, 1998). One of the participants explains: "...we work as a team. So we have a project leader...I'm part of a team and...do the data gathering...(but) most of the work that I do is basically myself because I specialise in a certain area of the application and I do most of the work myself." (Case Study 2 participant). This aspect of the persona of the virtual worker allows them, when the need arises, to contribute and adapt to both environments. One of the participants explains this ability of virtual workers to adapt to isolated, team, conventional and virtual arrangements. "Working like a virtual worker gives you an added advantage, it enables you to adapt to any working environment, you only need your tools and off you go to get the job done". (Case Study 2 participant).

\subsubsection{Communication Skills}

This dimension involves the nature of communication conducted by the virtual worker. Communication within the virtual environment is different to that of other work arrangements. It involves electronic communication and face-to-face meetings, although virtual workers often lack informal conversation opportunities (Fielding et al., 1998). One of the participants explains: "...informal social interactions between co-workers can be very productive in terms of getting work done, disseminating information, understanding what everybody else is working on and helping to feed that back into your own work." (Case Study 1 participant).

Wiesenfeld (1998) has found that increased communication strengthens organisational identification. This reliance on limited communication channels causes that participants some concern for new workers starting in a virtual organisation. For example on noted that "...much more limited exchange of information...somebody new coming in to the organisation...would be much more difficult for me to work with and develop...rapport." (Case Study 1 participant).

The virtual worker must be able to communicate electronically and be computer literate (Christie \& Levary, 1998), to build conversation, rapport and trust. One of the participants highlights the importance of communication in his role. "...means I find the client, I elicit the requirements, I build the model, I sell the model, I control the implementation. I make sure that there is no problem all the way through..." (Case Study 3 participant). The ability of the virtual worker to communication with clients is also required. Communications skills are required when meeting with clients, when collecting data and when presenting solutions to the client. Communication skills aid the virtual worker in conducting business. One of the participants notes: “...on the job 
you need to be able to express yourself and get to work with people on site as well..." (Case Study 2 participant).

\subsubsection{Organisational Experience}

This dimension deals with attributes that enable the virtual worker to cope with the nature of virtual organisations. Virtual organisations are flexible in structure, ever changing and dynamic (Davenport \& Pearlson, 1998). The virtual worker must enjoy being part of a dynamic organisation, which requires them to continuously learn and develop new skills to cope with increasingly unstable trends in business. One of the participants clarifies stating that: "...so I undergo continuous learning because I think that's important...you need to be able to continuously improve yourself." (Case Study 3 participant).

Virtual organisations take advantage of their flexible nature to take the opportunities that arise in changing markets (Dickerson, 1998). Experienced in change, not only of the organisation itself but in organisational dynamics, the nature and scope of work and previous experience allows the virtual worker to better deal with change. One of the participant's situation involves: "...we are all experienced professionals...coming in to it as a new person in the industry or as a graduate...it would be very hard for them to adjust...you have to be a good time manager..." (Case Study 3 participant). The virtual workers in this study feel that the virtual worker must enjoy this change, enjoy the nature of such work and to enjoy the challenge of virtual work. One of the participants clarifies: “...one thing to be able to survive and the most important thing I think is to be able to get the work you enjoy doing, that's most important, at the same time getting paid for the work you do." (Case Study 2 participant). The results of the study suggest that the virtual worker must, most importantly, enjoy the work and challenge that come with the position.

\subsubsection{Personal Traits}

The following dimension deals with the personal traits provided in the interviews. The virtual worker should exhibit some of the following attributes to enable them to perform in this environment. The virtual worker is disciplined, dedicated, and motivated to perform the work assigned (Christie \& Levary, 1998). Virtual work involves independent work. One of the participants summarises what attributes a virtual worker should exhibit. He noted: "...you have to be very dedicated...have to be fairly motivated...disciplined." (Case Study 3 participant). 
Further, they should have the flexibility and work ethic to research and solve complications that arise in their assignments without referring to superiors (Davenport \& Pearlson, 1998). One of the participants notes: "...need that kind of flexibility to be able to say...I've got to sit down, this is the work that I'm doing. If I can't figure out this problem or find a solution for it, then you actually have to sit down and do the research in your own time to solve the problem." (Case Study 2 participant). Virtual work requires that the virtual worker to be good managers of themselves and have the personality that enjoys the constant change, the challenge of assignments and the dynamics of a virtual organisation. Implying that the virtual worker is skilled in their chosen field, is task orientated in order to complete assignments and to excel in their work (Christie \& Levary, 1998). One of the participants comments about achieving: “.... if you succeed and, achieve and over achieve you stand out..." (Case Study 3 participant).

The persona of the virtual worker then appears to consist of four dimensions, each with its own set of attributes (Table 3). Further research is needed on the persona of the virtual worker to rigorously validate the findings of this study.

\section{CONCLUSIONS}

The main focus of this research has been to develop a deeper understanding of the effects virtual work on the virtual worker. In achieving this aim, the research unravelled the stories of three case studies involving virtual workers. Each story highlighted the background and future aspirations of the virtual workers. Attention was also paid to the profile of the virtual organisations, the role of information technology as the enabler of this new organisational form, the advantages and disadvantages of working virtually and the persona of the virtual workers interviewed as part of this study.

Autonomy and flexibility were suggested as the factors that were most important to the virtual worker. This related to autonomy to do their own work and flexibility to do their work when and where they chose. The main disadvantages discussed related to the isolation of the virtual environment, with the reliance on limited electronic communications, the lack of support and the lack of training contributing to the negative factors of virtual work. The discussion of the virtual worker persona was also reported in this paper. The persona of the virtual worker was reported to have four dimensions each with its own set of attributes salient to the ability of the virtual workers involved in this study to work virtually. 
This study attempted to develop a deeper understanding of the effects of virtual work on the virtual worker. In developing this understanding the advantages and disadvantages of virtual work and the persona of the virtual worker was explored. Through the discussion of these suggestions, which can be described as tentative, it is anticipated that a deeper understanding of virtual work has in fact been developed and will frame continuing research, especially as they related to the work processes and work flows becoming evident in newly developing e-businesses.

This study has tapped into only two sections of the findings of a much larger study. Future research may involve further investigation of the remaining sections. These may be the role of information technology in the virtual organisation, as enabler of new organisational structures or driver of new opportunities for the virtual worker. This study draws evidence from both perspectives. Other areas requiring further investigation may involve the complete definition of the virtual organisation. This study presented the work arrangements of the virtual workers. These arrangements or contractual relationships may be further explored. Future studies may involve either the salient aspects of virtual work arrangements or a framework for developing virtual arrangements in organising virtual workers. Alternately, future research may attempt to expand on the topics of interest discussed by the current research. This may involve developing a total picture of the virtual worker to further refine and expand on the dimensions of the virtual persona. Another avenue of further research may involve the use of the advantages and disadvantages found, to more rigorously validate them through quantitative research. This allows for the development of more generalisable and rigorous set of attributes. This will further strengthen the notion that virtual organisations are a viable structure in today's information technology driven economy.

In practice, the implementation of the virtual structures imposes a wholly different set of expectations onto the worker. From a relatively stable working environment to one that focuses on change may and has often caused great stress. Organisations need to consider how their workers view the advantages and disadvantages of virtual structures. Organisations must ask themselves:

- Will the implementation of these structures provide real gains for the organisation and the virtual workers?

- What are the views of the current workforce?

- Are the advantages seen in this study seen by their employees?

These questions may guide organisations in implementing virtual structures, to ensure that the benefits of virtual work outweigh the disadvantages as evident in this study. 
Understanding the persona of the virtual worker will also enable organisations considering virtual structures to assess the mental readiness of their employees. Questions organisations may ask of their employees may involve:

- Can adequate communication norms be developed to handle the reliance on electronic communications in virtual environments?

- Are the experiences of the employees able to cope with constant change?

- Do the employees exhibit the personal traits found in this study of virtual workers?

\section{REFERENCES}

Ahuja, M. K., \& Carley, K. M., (1998) "Network and Structure in Virtual Organisations." Journal of Computer Mediated Communication, Volume 3, Issue 4, June.

Applegate, L. M., McFarlan, F. W., \& McKenney, J. L., (1999) “Corporate Information Systems Management, Text and Cases." 5th edition, USA: Irwin McGraw-Hill.

Becker, S. H., (1996) "The Epistemology of Qualitative Research." in Jessor, R., Colby, A., \& Schweder, R., (Eds) "Essays on Ethnography and Human Development." University of Chicago Press, Chicago.

Boudreau, M. C., Loch, K. D., Robey, D., \& Straud, D., (1998) "Going Global: Using Information Technology to Advance the Competitiveness of the Virtual Transnational Organisation." The Academy of Management Executive, Volume 12, Issue 4, November.

Brousseau, E., (1990) "Information technologies and inter-firm relationships: The spread of inter-organisational telematics systems and its impact on economic structure." Paper presented to the International Telecommunications Society, Venice, June.

Bultje, R., \& van Wijk, J., (1998) "Taxonomy of Virtual Organisations, based on definitions, characteristics and typology." in: VoNet: The Newsletter@www.virtual-organization.net, Volume 2, Number 3.

Burrell, G., \& Morgan, G., (1979) "Sociological Paradigms and Organisational Analysis." Heinemann, London.

Byrd, K., \& Gulbro, R. D., (1998) "E-mail and the Organisation of Tomorrow." Ivey Business Quarterly, Volume 63, Issue 1, Autumn.

Castells, M (2001) The Internet Galaxy, Oxford, OUP.

Checkland, P., (1981) "Systems Thinking, Systems Practice." John Wiley and Sons, Chichester.

Christie P. M. J., \& Levary R. R., (1998) "Virtual Corporations: Recipe for Success." Industrial Management, Volume. 40, Number 4.

Compeau, D., Higgins, C. A., \& Huff, S., (1999) "Social cognitive theory and individual reactions to computing technology: A longitudinal study." MIS Quarterly, Minneapolis, Volume 23, Issue 2, June.

Davenport, T. H., \& Pearlson, K., (1998) "Two cheers for the virtual office." Sloan Management Review, Cambridge, Volume 39, Issue 4, Summer.

Davidow, W., \& Malone, M., (1992) “The Virtual Corporation." New York: Harper Collins.

Dennis, A., Pootheri, S., \& Natarajan, V., (1998) "Lessons from the Early Adopters of Web Groupware.” Journal of Management Information Systems, Volume 14, Number 4, Spring. 
DeSantis, G., \& Monge P., (1998) "Communication Processes for Virtual Organisations." Journal of Computer Mediated Communication, Volume 3, Issue 4, June.

Dickerson, C. M., (1998) "Virtual Organisations: From Dominance to Opportunism." New Zealand Journal of Industrial Relations, Volume 23, Issue 2, June.

Eisenhardt, K. M., (1989) "Building Theories from Case Study Research." Academy of Management Review, Volume 14, Issue 4.

Erben, K., \& Gersten, K., (1997) "Cooperation Networks towards Virtual Enterprises." in VONet: The Newsletter, Volume 1, Number 5, December, @ www.virtualorganization.net.

Fielding, R. T., Whitehead, Jr. J. E., Anderson, K. M., \& Bolcher, G. A., (1998), "Web-based development of complex information products." Association for Computing Machinery. Communications of the ACM, New York, Volume 41, Issue 8, August.

Fritz, M., Narasimhan, S., \& Rhee, H., (1998) "Communication and Coordination in the Virtual Office." Journal of Management Information Systems, Volume 14, Number 4, Spring.

Gallegos, F., \& Powell, S. R., (1997) "Telecommunications Networks in Virtual Corporations. " IS Audit \& Control Journal, Volume 3.

Galliers, R., (Ed.), (1992) "Information systems research: Issues, methods, and practical guidelines." Blackwell Scientific Publications, Oxford.

Gersick, C. J. G., (1988) "Time and transition in work teams: Toward a new model of group development." Academy of Management Journal, Volume 31, Issue 2.

Glaser, B. G., (1992) "Emergence vs Forcing: Basics of Grounded Theory Analysis." Sociology Press.

Glaser, B. G., \& Strauss, A., (1967) "The Discovery of Grounded Theory: Strategies for Qualitative Research." Aldine Publishing Co, Chicago.

Glaser, B. G., (1978) "Theoretical Sensitivity: Advances in the Methodology of Grounded Theory." CA: The Sociology Press, Mill Valley.

Goldman, S. L., Nagel, R. N., (1993) "Management, technology and agility: the emergence of a new era in manufacturing." International Journal of technology Management, Volume 8, Numbers $1 / 2$.

Goodman, P. S., \& Darr, E. D., (1998) "Computer-aided systems and communities: Mechanisms for organisational learning in distributed environments." MIS Quarterly, Minneapolis, Volume 22, Issue 4, December.

Grabowski, M., \& Roberts, K., (1998) "Risk Mitigation in Virtual Organisations." Journal of Computer Mediated Communication, Volume 3, Issue 4, June.

Gummesson, E., (1988) "Qualitative Methods in Management Research." Studentlitteratur, Stockholm.

Hamilton, S., \& Ives, B., (1982) "MIS Research Strategies.” Information \& Management, Volume 5 .

Hart, P., \& Estrin, D., (1991) "Inter-organizational networks, computer integration, and shifts in interdependence: The case of the semiconductor industry." ACM Transactions on Information Systems, Volume 9, Issue 4.

Hartman, F., \& Guss, C., (1996) "Virtual teams - constrained by technology or culture." Proceedings of IEMC 96, "Managing virtual enterprises: A convergence of communications, computing and energy technologies." Vancouver, BC, Canada: IEEE.

Hill, J. E., Miller, B. C., Weiner, S. P., \& Colihan, J., (1998) "Influences of the virtual office on aspects of work and work/life balance." Personnel Psychology, Durham, Volume 51, Issue 3, Autumn. 
Hirscheim, R., \& Klein, H., (1992) "A Research Agenda for Future Information Systems Development Methodologies." In Cotterman, W. W., Senn, J. A., (Eds) "Challenges and Strategies for Research in Systems Development." John Wiley and Sons, Chichester.

Jansen, Steenbakkers \& Jagers, (1999) "Electronic Commerce and Virtual Organisations." Proceedings of the $2^{\text {nd }}$ International VoNet-Workshop, Zurich, Special Issue eJOV, Volume 1, Number 1, September.

Jarvenpaa, S. L., \& Leidner, D. E., (1998) "Communication and Trust in Global Virtual Teams." Journal of Computer Mediated Communication, Volume 3, Issue 4, June.

Jarvenpaa, S. L., Ives, B., \& Pearlson, K., (1995) "Global customer service for the computer and communications industry." in Palvia, P. C., Palvia, S. C., \& Roche, E. M., (Eds.), "Global information technology and systems management." Ivy League Publishing, Harrisburg.

Jarvenpaa, S., Knoll, K., \& Leidner, D., (1998) "Is anybody out there? Antecedents of Trust in Global Virtual Teams." Journal of Management Information Systems, Volume 14, Number 4, Spring.

Kaplan, B. and Duchon, D., (1988) "Combining Qualitative and Quantitative Methods in Information Systems Research: A Case Study." MIS Quarterly, Volume 12, Issue 4.

Kekre, S., \& Mudhopadhyay, T., (1992) "Impact of electronic data interchange technology on quality improvement and inventory reduction programs: A field study." International Journal of Production Economics, Volume 28.

Klein, H. K. \& Myers, M. D., (1999) "A set of principles for conducting and evaluating interpretive field studies in information systems." MIS Quarterly, Minneapolis, Volume 23, Issue 1, March.

Kraut, R., Steinfield, C., Chan, A., Butler, B., \& Hoag A., (1998) "Coordination and Virtualisation: The Role of Electronic Networks and Personal Relationships." Journal of Computer Mediated Communication, Volume 3, Issue 4, June.

Lacity, M. C., \& Janson, M. A., (1994) "Understanding Qualitative Data: A Framework of Text Analysis Methods.” Journal of Management Information Systems, Volume 11, Issue 2, Fall.

Lee, A. S., (1994) "Electronic Mail as a Medium for Rich Communication: An Empirical Investigation Using Hermeneutic Interpretation." MIS Quarterly, Volume 18, Issue 2, June.

Leedy, P. D., (1997) "Practical Research: Planning and Design." Sixth Edition, Prentice Hall, New Jersey.

Lin, C. A., (1998) "Bridging the Positivist and Interpretivist Approaches to Qualitative Methods." Policy Studies Journal, Volume 26, Number 1.

Lipnack, J., \& Stamps, J., (1999) "Virtual teams." Executive Excellence, Provo, Volume 16, Issue 5, May.

Malone, T., \& Rockart, J., (1993) "How will information technology reshape organisations? Computers as coordination technology." in Bradley, S., Hausman, J., \& Nolan, R., (Eds.), "Globalisation, technology and competition: The fusion of computers and telecommunications in the 1990s." Harvard University School Press, Boston.

Malone, T., Yates, J., \& Benjamin, R., (1987) "Electronic markets and electronic hierarchies: Effects of information technology on market structure and corporate strategies." Communications of the ACM, Volume 30, Issue 6.

Meyerson, D., Weick, K. E., \& Kramer, R. M. (1996) "Swift trust and temporary groups." in Kramer, R. M., \& Tyler, T. R., (Eds.) "Trust in organisations: Frontiers of theory and research." Sage Publications, Thousand Oaks. 
Myers, M. D., (1997) “Qualitative Research in Information Systems.” MIS Quarterly, Volume 21, Issue 2, June. MISQ Discovery, archival version, June 1997, @ www.misq.org/misqd961/isworld/. MISQ Discovery, updated version, April 28, 1999, @ www.auckland.ac.nz/msis/isworld/.

Neuman, W. L., (1991) "Social Research Methods: Qualitative and Quantitative Approaches." Allyn and Bacon, Massachusetts.

Nohria, N., \& Berkley, J.D., (1994) "The Virtual Organisations: bureaucracy, technology, and the Implosion of Control." in Helscher, C., \& Donnellon, A., (Eds.) "The PostBureaucratic Organisation: New Perspectives in Organisational Change." Sage, Thousand Oaks.

Orlikowski, W. J. \& Baroudi, J. J. (1991). "Studying Information Technology in Organisations: Research Approaches and Assumptions." Information Systems Research, Volume 2.

Palmer J. W. and Speier C. H., (1997) "A Typology of Virtual Organisations: An Empirical Study." in Proceedings of the Association for Information Systems 1997 Americas Conference, Indianapolis, August.

Patton, M. Q., (1990) "Qualitative Evaluation and Research Methods." (2 ${ }^{\text {nd }}$ Ed.) Sage Publications, Newbury Park.

Pettigrew, A., (1988) “ Longitudinal field research on change: Theory and practice." Paper presented at the National Science Foundation Conference on Longitudinal Research Methods in Organisations, Austin.

Plishkin, N., \& Romm, C.T., (1997) "The impact of e-mail on the evolution of a virtual community during a strike." Information and Management, Volume 32.

Powell S., \& Gallegos F., (1998) "Securing Virtual Corporation." Information Strategy, Volume 14, Number 4.

Rittenbruch, M., Kahler, H., \& Cremers, A. B., (1998) "Supporting Cooperation in a Virtual Organisation." in Hirschheim, R., Newman, M., \& DeGross, J. I., (Eds.) "Proceedings of the Nineteenth International Conference on Information Systems. " Helsinki, Finland.

Shanks, G., Rouse, A., \& Arnott, D., (1993) "A Review of Approaches to Research and Scholarship in Information Systems." Proc. $4^{\text {th }}$ Australian Conference on Information Systems, Brisbane.

Staples D. S., Hulland J. S., \& Higgins C. A., (1998) "A Self-Efficacy Theory Explanation for the Management of Remote Workers in Virtual Organisations." Journal of Computer Mediated Communication, Volume 3, Issue 4, June.

Steinfield, C., Kraut, R., \& Plummer, A., (1995) "The impact of interorganisational networks on buyer-seller relationships." Journal of Computer Mediated Communication [Online], Volume 1, Issue 3.

Stoddard, D. B., \& Donnellon, A., (1997) “Verifone.” Harvard Business School, 9-398-030, Harvard Business School Publishing, Boston.

Strauss A., (1987) "Qualitative Analysis for Social Scientists." Cambridge University Press, Cambridge.

Strauss, A., \& Corbin, J., (1990) "Basics of Qualitative Research: Grounded Theory Procedures and Techniques." Sage Publications, Newbury Park.

Streeter, L. A., Kraut, R. E., Lucas, H. C., \& Caby, L., (1996) "The impact of national data networks on firm performance and market structure." Communications of the ACM.

Stroh, K. L., \& Caligiuri, P. M., (1998) "Increasing global competitiveness through effective people management." Journal of World Business, Greenwich, Volume 33, Issue 1, Spring. 
Townsend A. M., DeMarie S. M., \& Hendrickson A. R., (1998) "Virtual teams: Technology and the workplace of the future." The Academy of Management Executive, Ada, Volume 12, Issue 3, August.

Urquhart, C., (1996) "Exploring Analyst-Client communication: using grounded theory techniques to investigate interaction in informal requirements gathering." $A C I S$, Conference. Proceedings

Van Alstyne, M., and Brynjolfsson, E., (1996) "Electronic Communities: Global Villages or Cyberbalkanisation?" International Conference on Information Systems, 1996 Proceedings.

Vandenbosch, B., and Ginzberg, M.J., (1997) "Lotus Notes and Collaboration." Journal of Management Information Systems, Volume 13, Number 3, Winter.

Venkatraman, N., \& Hendersen C.J., (1998) "Real strategies for virtual organizing." Sloan Management Review, Cambridge, Volume 40, Issue 1, Fall. 